4. The gleam sometimes emitted by hailstones is due also to electricity; for although in the experiments described, it could not be distinguished whether the globules were self-luminous or shone by the reflection of the spark, it is probatle that they were also rendered phosphorescent by the electric current which they contained.

M. Plante admits the action of other agents, such as wind currents, in the formation of hail, but only as accessories to the action of electricity. They are concurrent causes which only prepare the conditions favourable to its production, while electricity is the efficient cause which, by its very presence in the clouds and by the instantaneous power of its discharges, determines the sudden formation and the fall of the meteor.

M. Planté is still prosecuting his researches on this subject.

(To be continued.)

\section{ENTOMOLOGY IN AMERICA}

$T^{H E}$ E U.S. Entomological Commission which was organised and placed under the auspices of Prof. Hayden's Geological Survey for the purpose of investigating and reporting the entire subject of insect ravages throughout the western regions of our continent, have completed their field labour for the present season.

The members of the Commission have been busily engaged in the preparation of the several parts of their Annual Report, and will soon meet in Washington, where they will have a protracted sitting to get everything ready for the printer. This report is looked for with much interest by the farmers of the west, and the character of the commissioners is a guarantee that it will be creditable from the scientific, and valuable from the piactical, stand. point. The Report will contain sixteen chapters, tunder the following heads:--Introduction, Riley; Chronological History, Packard; Statistics of Losses, Thomas ; Classification and Nomenclature, Thomas ; Georraphical Distribution, Thomas and Packard; Migration and Meteorology, Packard and Thomas; Original Permanent Breeding Grounds, Riley, Packard, and Thomas; Habits and Natural History, Kiley; Embryology, l'ackard ; Metamorphoses, Riley and Packard; Invertebrate Enemies, Riley; Vertebrate Enemies, Thomas; Remedies and Devices for Destruction, Riley; Prairie Fires wersus Locust Injury, Riley; Agricultural Bearings of the Subject, Thomas; Ravages of other Locusts, Packard and Riley; Locust Ravages in other Countries.

These chapters will embrace many sub-chapters, and the Report will be as exhaustive as the limited time for its preparation will permit.

In Chapter IV. the western extension and the northern and eastern limit of the species' range are fully given.

In Chapter $V$. the laws governing its migrations are for the first time defined. A very Jarge number of data have been collected in reference to the subjects of this chapter. Not only are the general laws governing the movements of the insect now defined, showing a regular migration southward and return migration northward, which may be counted on and foreseen ; but many important and highly interesting facts in reference to their local flights are brought to light, which will henceforward form a part of the history of the insect.

In Chapter VII. several other laws governing the species are also adduced; and the importance of the discovery of the laws which regulate the doings and movements of the pest, cannot be over-estimated. In said Chapter VII. many new facts will for the first time appear, and all that is definite and accurate be made known.

In Chapter X. many new discoveries will be recorded, some of them of great scientific interest and importance. Of these may be mentioned the transformation of the silky mite (Trombidium scriceum). This is an eightlegged creature, which preys on the locust eggs. It is proved to be the mature form of the little six-legged mite (Astona gryllaria) which is parasitic on the locust. Insects described under different genera are thus proved to be specifically identical. The life-history of the blisterbeetles will also be given, their larvæ feeding upon locust eggs, and undergoing singular changes called hypermetamorphoses. The interest attaching to this discovery among entomologists, as well as among farmers, is best appreciated when it is considered that absolutely nothing has heretofore been known of the larval habits of these blister-beetles, notwithstanding the fact that for half a century much attention has been given to the subject by scientific men, on account of the commercial value of Cantharis, or Spanish fly, and of the great injury to potatoes and other plants committed by several of oar American species.

In Chapter XI. are given the locust feeding habits of many western animals not heretofore known to have that habit, and the good offices of birds are especially made manifest, examinations of the stomachs of over ninety species and 630 specimens having been made with special reference to their locust-eating habits. The record in reference to these examinations is very full, giving the dates, the locality, the common and scientific names of the species, and the number of locusts and other insects found in each. The value heretofore placed on these aids by entomologists is fully sustained by this record.

In Chapter XII., which will be one of the most extended and most important practically, it is clearly shown that the young locusts may be controlled, and by what means: while the way is pointed out how to better control the winged insects. Many valuable devices for destruction will be illustrated, among them one invented by Prof. Riley, which gave great satisfaction, and will, it is believed, supersede all others as a cheap and practicable remedy applicable at any season, whether the plants or the insects be small or large.

In Chapters II, and IV. are given statistics showing the immense losses inflicted on western agriculturists by the locust. These chapters also show what crops are most liable to injury and what are most easily protected; also the best methods of cropping in order to reduce the injury to a minimum. A chemical analysis of the dead locusts has been made, and is unusually interesting. The insects furnish a new oil, which will be christened Coloptine, and a very large per-centage of pure formic acid. Though this acid exists in the ant and some other insects, it is with difficulty obtained in large quantities, whereas by the action of sulphuric acid upon the locust juices it passes off with great readiness and in remarloable quantity and gravity. The various uses of this acid whether as a therapeutic agent or as laboratory re-agents; \&c., are capable of great and valuable extension when it can once be obtained so readily and in such quantity.

The Report is expected to make about 500 pages, and will, it is hoped; be published in February or March. Although the Commissioners have' divided the labour among them, the Report will form one complete whole, as the work of each will be discussed and revised by the Commission as a whole.

The Annual Report, which is intended more particularly for the practical farming public, will be followed by memoirs of a more purely scientific nature-one by $\mathrm{Dr}$ Packard on Anatomy and Embryology; one by Prof. Ruley on the Natural History of other Locusts, and one by Prof. Thomas on the classification of the Acrididee.

While it has been the object of the Commission to cover as much ground as possible so as to make the Annual Report as full and valuable as the time would permit, there yet remain several important subjects that it has so far been impossible to properly and exhaustively study. The territory affected is so vast, embracing over 
a miliion square miles, that much of it was imperfectly explored, especially in the north-west. Mr. Riley had to cut short his investigations in British America both for want of time and want of funds. For similar reasons, and on account of Indian troubles, Montana, Wyoming, and Dakota, have been but superficially explored.

The year 1877 was an abnormal year, i.e. the insect had, the previous year, overrun a large section of country in which it is not indigenous, hatched in such country in the spring. This was most fortunate for many reasons, as it enabled the Commission to carefully study the insects in this their unnatural condition, and to carry on experiments with a view of learning how to control them. Much of the work of the Commission was with these young insects. The losses sustained through the devastation of the pest by young and struggling frontier populations, ill able to bear them, were immense; and there was so much discouragement that hundreds and thousands of persons were on the point of abandoning their new homes last spring. At this juncture the Commission went into the field, and by its encouraging predictions (which were all verified) and recommendations, imbued the people with hope and confidence, and drew westward again the emigration that had almost stopped. All this work, however, interfered with needed investigations into the proper range, the native home and breeding grounds, the source of swarms, and many other important questions which can only be properly studied during a normal year. It is, therefore, very important that the investigations be continued until every question is settled that human investigation can settle.

For the proper settlement of some of the questions the co-operation of the Dominion Government is desirable, and has been promised by the Canadian authorities if the work of the Commission should continue.

It will be unwise to stop the work of the Commission before completed. The work should be made so thorough as to obviate any necessity in future years of creating another commission for the same purpose. After careful estimates it is conciuded that the work can be satisfactorily completed only with two more years' investigation and experiment. The Commission therefore ask for a continuance of the appropriation of 25,000 dols. asked for a year ago.

There are various other injurious insects of national importance, of which much has yet to be learned, and in addition to completing the locust investigation, the Commission contemplate, during the coming two years, studying and reporting on some of these worst enemies to American agriculture. They are especially desirous of reporting on the cotton-worm of the south, which, though often so disastrous to the cotton crop, has never been fully studied, and in the mere natural history of which there are yet many mysteries and conflicting theories.

Much has yet to be done in giving practical form to the conclusions arrived at and plans proposed by the Commission to enable the work already done to bear proper fruit. To bring about the needed co-operation of the two Governments, to cause proper laws to be enacted in all the states interested, and to enforce the truths that alone will make man master of the situation, is largely the work of the future.

\section{SOUNDING APPARATUS}

THAT Sir William Thomson's recent application of 1 the pianoforte wire to sounding in small depths for the ordinary purposes of navigation is of great value, will be admitted readily by those who are familiar with the present process. But it occurs to me that a formidable objection to its general introduction into naval or mercantile vessels is to be found in the necessity of using chemically-prepared tubes for determining the depth of water. Sir William's latest device is (I believe) a straight glass tube two feet long, open at one end and irclosed in a brass tube attached above the sinker, in which air is compressed by the pressure of the water, the amount of compression being determined by the height to which the water rises in the tube. This height is marked by the decolorisation of a coating of chromate of silver on the inside of the tube, effected by the sea-water. A number of such tubes, properly prepared, must therefore be kept at hand, and when once used they must be coated anew, an operation of no little difficulty.

I have suggested a form of sinker in which these objections are obviated, while the principle is retained. The sinker is of iron three inches in diameter at the bottom, five inches at the top, and 26.5 inches long. It is cast with a cylindrical cavity, two inches in diameter, extending from the top to within an inch of its base. This cavity contains the glass tube by which the depth is determined. A tube about forty-eight inches long is taken, closed at one end and bent back on itself at its middle point, so as to make two legs each twenty-four inches in length. This is placed inside the sinker (the bend up. ward) and a screw tap, carrying a swivellink for the sounding line, is screwed over it. Holes in the bottom of the sinker and through the screw tap allow the water access to the tube. As the sinker descends, in sounding, the air within the tube is compressed and the water rises in the open leg. When the column of water reaches the highest point of the bend, the pressure then corresponding to a depth of about five and a half fathoms, any further descent of the sinker will cause the water to pass over into the lower end of the closed leg. The compression of the air will then take place in the upper part of the closed leg, the maximum compression being indicated by the length of the column of water remaining in that leg when the sinker is lifted again to the surface. As the sinker is being raised, the air, expanding under the diminished pressure, drives the water out of the open leg. The inside and outside pressures are therefore equal at any instant. The tube may bo graduated in inches and tenths, and a table will give the depth from the reading of the tube. The tube is then easily emptied and is ready for another cast. The form of the sinker is such that the bend of the tube is kept at a higher level than the open end in case the sinker should fall over when it reaches the bottom-the entrance of surplus water is thus prevented. An ordinary cup attachment for a bottom specimen can be applied to the end of the sinker.

The tube described will not indicate a depth less than five and a half fathorns. If it is desired to obtain casts in shoaler water a tube with the open leg shorter than the closed leg may be used. One in which the length of the open leg is one-fourth that of the closed leg will indicate depths of two fathoms and upwards.

I am aware that Sir Wm. Thomson has a tube for bringing up the column of water, but it requires the use of valves, which can never be kept tight under such enormous pressures as those to which the sounding-tubes are exposed.

I inclose a sectional drawing of the above-described tube and sinker.

Theo. F. Jewel L, Lieut. Com. U.S. Navy 